Biological Child Psychiatry 


\section{Advances in Biological Psychiatry}

Vol. 24

Series Editors

D. Ebert Freiburg

K.P. Ebmeier Oxford

W.F. Gattaz são Paulo

W.P. Kaschka Ulm 


\section{Biological Child Psychiatry Recent Trends and Developments}

Volume Editors

T. Banaschewski Mannheim

L.A. Rohde Porto Alegre

8 figures and 13 tables, 2008

KARGER 


\author{
Prof. Dr. Dr. Tobias Banaschewski \\ Department of Child and Adolescent \\ Psychiatry and Psychotherapy \\ Central Institute of Mental Health \\ PO Box 122120 \\ DE-68072 Mannheim (Germany)
}

Prof. Dr. Luis Augusto Rohde Child and Adolescent Psychiatric Division Hospital de Clinicas de Porto Alegre Rua Ramiro Barcelos, 2350

Porto Alegre, RS 90035-003 (Brazil)

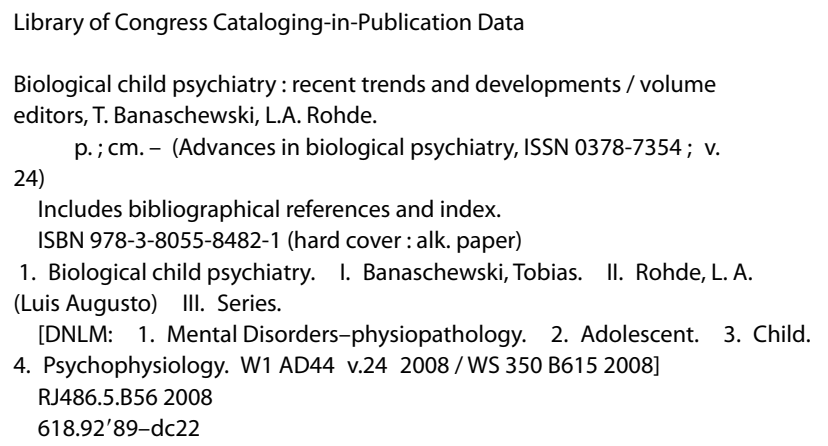

2007049800

Bibliographic Indices. This publication is listed in bibliographic services, including Current Contents ${ }^{\circledR}$ PubMed/MEDLINE

Disclaimer. The statements, options and data contained in this publication are solely those of the individual authors and contributors and not of the publisher and the editor(s). The appearance of advertisements in the book is not a warranty, endorsement, or approval of the products or services advertised or of their effectiveness, quality or safety. The publisher and the editor(s) disclaim responsibility for any injury to persons or property resulting from any ideas, methods, instructions or products referred to in the content or advertisements.

Drug Dosage. The authors and the publisher have exerted every effort to ensure that drug selection and dosage set forth in this text are in accord with current recommendations and practice at the time of publication. However, in view of ongoing research, changes in government regulations, and the constant flow of information relating to drug therapy and drug reactions, the reader is urged to check the package insert for each drug for any change in indications and dosage and for added warnings and precautions. This is particularly important when the recommended agent is a new and/or infrequently employed drug.

All rights reserved. No part of this publication may be translated into other languages, reproduced or utilized in any form or by any means electronic or mechanical, including photocopying, recording, microcopying, or by any information storage and retrieval system, without permission in writing from the publisher.

(c) Copyright 2008 by S. Karger AG, P.O. Box, CH-4009 Basel (Switzerland)

www.karger.com

Printed in Switzerland on acid-free and non-aging paper (ISO 9706) by Reinhardt Druck, Basel

ISSN 0378-7354

ISBN 978-3-8055-8482-1 


\section{Contents}

VII Preface

1 Attention-Deficit/Hyperactivity Disorder

Coghill, D. (Dundee); Rohde, L.A. (Porto Alegre); Banaschewski, T. (Mannheim)

21 Autism

Moura, P.J. (São Paulo/New Haven, Conn.); Lombroso, P.J. (New Haven, Conn.);

Mercadante, M.T. (São Paulo)

39 Brain Model for Pediatric Bipolar Disorder

Pavuluri, M.N.; Bogarapu, S. (Chicago, III.)

53 Neurobiology of Depression in Childhood and Adolescence

Bark, C.; Resch, F. (Heidelberg)

67 The Neurobiological Basis of Anxiety in Children and Adolescents

Grados, M.A. (Baltimore, Md.)

82 Obsessive-Compulsive Disorder in Childhood

Rosário, M.C.; Alvarenga, P.; Mathis, M.A. (São Paulo);

Leckman, J. (New Haven, Conn.)

95 Neurobiological Background of Tic Disorders

Roessner, V.; Rothenberger, A. (Goettingen)

118 Schizophrenia in Children and Adolescents

Remschmidt, H. (Marburg)

138 Eating Disorders

Fleitlich-Bilyk, B. (São Paulo); Lock, J. (Stanford, Calif.)

153 Conduct Disorder

Popma, A. (Amsterdam); Vermeiren, R. (Leiden)

166 Substance Use Disorders in Adolescence

Szobot, C.M. (Porto Alegre); Bukstein, O. (Pittsburgh, Pa.) 
181 Molecular Genetics in Child Psychiatry

Stringaris, A.K.; Asherson, P. (London)

195 Recent Developments in Neuropsychological Models of

Childhood Psychiatric Disorders

Willcutt, E.G. (Boulder, Colo.); Sonuga-Barke, E.J.S. (Southampton/New York, N.Y./

London/Ghent); Nigg, J.T. (East Lansing, Mich.); Sergeant, J.A. (Amsterdam)

227 Electrophysiology in Child Psychiatric Disorders

Banaschewski, T. (Mannheim); Brandeis, D. (Zürich)

238 Neuroimaging in Child Psychiatry

Durston, S. (Utrecht)

250 Author Index

251 Subject Index 


\section{Preface}

Several epidemiological studies have documented that mental health disorders are extremely prevalent in children and adolescents with rates varying from 10 to $20 \%$ depending on whether the evaluation of impairment is part of the assessment $[1,2]$. In addition, data from longitudinal studies and retrospective investigations in adulthood have demonstrated that a substantial proportion of psychiatric diagnoses identified in adults have their roots in childhood and adolescence [3, 4]. Moreover, several reports in the literature have also documented the substantial amount of burden that child mental health problems impose on children, their families and society in general [5]. Thus, understanding child psychiatric disorders is a priority in the worldwide mental health agenda based on its prevalence, continuity into adulthood and impact.

Throughout the last decades, several different frameworks have influenced the field of child psychiatry. In the past, the field was strongly based on psychodynamic and social concepts [6]. In the last two decades, an enormous amount of data has emerged in areas such as neuroimaging, molecular genetics, neuropsychology, and neurophysiology, helping to better understand the biological basis of the majority of child mental disorders. Thus, we have moved from attributing the causes of severe child mental disorders like autism primarily to problematic mother-infant relationships to an era in which huge genome-wide scanning studies and longitudinal geneenvironmental investigations are beginning to reveal the complex interplay of nature and nurture in normal development and in the etiology of child mental disorders [7]. Advances in biological child psychiatry may ultimately facilitate our understanding of how environmentally and psychosocially mediated risk processes operate on the developing brain and also increase our knowledge of the developmental trajectories that occur across the life course [8].

In this exciting context, the authors of this book wrote their chapters. They are among the world's leading experts, both researchers and clinicians, in the area of 
biological child psychiatry. While some contributors focused exclusively on recent biological aspects of specific disorders, others preferred a more comprehensive approach describing some clinical aspects too. However, independent of the approach chosen, the reader will always find the most recent advances in neurobiological research on each of the disorders addressed in this book.

During the rapid development of child psychiatry in the last decade, investigators have also paid special attention to the impact of cross-cultural issues on the development and/or modulation of phenotype or course of child mental disorders [9]. This is another interesting aspect of this book, since the team of authors came from very diverse cultural backgrounds and, whenever possible, we tried to have authors from different cultures address specific disorders.

Finally, a very relevant issue is related to what is called 'translation research'. In other words, how very sophisticated basic laboratory findings translate into clinical practice [10]. Although the focus of this volume is on child biological psychiatry, the authors tried to present findings in an integrative context helping readers to establish the needed connections with the real clinical world.

For all the reasons mentioned above, we are confident that this book will be valuable to all practitioners and researchers both in child and adolescent mental health services and developmental and clinical neuroscience who are interested in deepening their knowledge of the recent advances in the underlying biological bases of major child and adolescent mental health disorders.

Luis Augusto Rohde, Porto Alegre

Tobias Banaschewski, Mannheim

\section{References}

1 Belfer ML, Saxena S: WHO Child Atlas Project. Lancet 2006;367:551-552.

2 Fleitlich-Bilyk B, Goodman R: Prevalence of child and adolescent psychiatric disorders in southeast Brazil. J Am Acad Child Adolesc Psychiatry 2004;43: 727-734.

3 Kessler RC, Berglund P, Demler O, Jin R, Merikangas KR, Walters EE: Lifetime prevalence and age-of-onset distributions of DSM-IV disorders in the National Comorbidity Survey Replication. Arch Gen Psychiatry 2005;62:593-602.

4 Kim-Cohen J, Caspi A, Moffitt TE, Harrington H, Milne BJ, Poulton R: Prior juvenile diagnoses in adults with mental disorder: developmental followback of a prospective-longitudinal cohort. Arch Gen Psychiatry 2003;60:709-717.

5 Prince M, Patel V, Saxena S, Maj M, Maselko J, Phillips MR, Rahman A: No health without mental health. Lancet 2007;370:859-877.
6 Eisenberg L: The past 50 years of child and adolescent psychiatry: a personal memoir. J Am Acad Child Adolesc Psychiatry 2001;40:743-748.

7 Caspi A, Moffitt T: Gene-environment interactions in psychiatry: joining forces with neuroscience. Nat Rev Neurosci 2006;7:583-590.

8 Rutter M: Categories, dimensions, and the mental health of children and adolescents. Ann NY Acad Sci 2003;1008:11-21.

9 Rohde LA, Szobot C, Polanczyk G, Schmitz M, Martins S, Tramontina S: Attention-deficit/hyperactivity disorder in a diverse culture: do research and clinical findings support the notion of a cultural construct for the disorder? Biol Psychiatry 2005;57: 1436-1441.

10 Porges SW: Asserting the role of biobehavioral sciences into translational research: the behavioral neurobiological revolution. Dev Psychopathol 2006; 18:923-933. 